\title{
Increased TPSAB1 Copy Number in a Family With Elevated Basal Serum Levels of Tryptase
}

\author{
Laura Hernández-Hernández 1,2, Catalina Sanz 2,3, Elena Marcos-Vadillo ${ }^{2,4}$, \\ Asunción García-Sánchez ${ }^{2,5}$, Esther Moreno ${ }^{1,2,4,5}$, Félix Lorente ${ }^{1,2,5}$, \\ David González-de-Olano ${ }^{6}$, Ignacio Dávila ${ }^{1,2,5 *}$ and María Isidoro-García ${ }^{2,4,7}$
}

${ }^{1}$ Department of Allergy, University Hospital of Salamanca, Salamanca, Spain, ${ }^{2}$ Institute for Biomedical Research of Salamanca (IBSAL), Salamanca, Spain, ${ }^{3}$ Department of Microbiology and Genetics, University of Salamanca, Salamanca, Spain, ${ }^{4}$ Department of Clinical Biochemistry, University Hospital of Salamanca, Salamanca, Spain, ${ }^{5}$ Department of Biomedical and Diagnostics Sciences, University of Salamanca, Salamanca, Spain, ${ }^{6}$ Department of Allergy, Instituto Ramón y Cajal de Investigación Sanitaria (IRYCIS), University Hospital Ramón y Cajal, Madrid, Spain, ${ }^{7}$ Department of Medicine, University of Salamanca, Salamanca, Spain

Background: Some recent familial studies have described a pattern of autosomal dominant inheritance for increased basal serum tryptase (BST), but no correlation with mRNA expression and gene dose have been reported.

Objective: We analyzed TPSAB1 mRNA expression and gene dose in a four-member family with high BST and in two control subjects.

Evi X. Stavrou,

Case Western Reserve University,

United States

Reviewed by:

Long-Sheng Lu,

Taipei Medical University, Taiwan

Alvin H. Schmaier,

Case Western Reserve University,

United States

*Correspondence: Ignacio Dávila idg@usal.es

Specialty section:

This article was submitted to Hematology,

a section of the journal

Frontiers in Medicine

Received: 28 June 2020 Accepted: 19 March 2021

Published: 13 April 2021

Citation:

Hernández-Hernández L, Sanz C Marcos-Vadillo E, García-Sánchez A,

Moreno $E$, Lorente $F$

González-de-Olano D, Dávila I and Isidoro-García M (2021) Increased

TPSAB1 Copy Number in a Family

With Elevated Basal Serum Levels of

Tryptase. Front. Med. 8:577081.

doi: 10.3389/fmed.2021.577081
Methods: Blood samples were collected from the family and control subjects. Complete morphologic, immunophenotypical, and molecular bone marrow mast cell (MC) studies were performed. mRNA gene expression and gene dose were performed in a LightCycler 480 instrument. Genotype and CNV were performed by quantitative real-time digital PCR (qdPCR).

Results: CNV analysis revealed a hereditary copy number gain genotype $(3 \beta 2 \alpha)$ present in all the family members studied. The elevated total BST in the family members correlated with a significant increase in tryptase gene expression and dose.

Conclusions and Clinical Relevance: We present a family with hereditary $\alpha$-tryptasemia and elevated BST which correlated with a high expression of tryptase genes and an increased gene dose. The family members presented with atypical MC-mediator release symptoms or were even asymptomatic. Clinicians should be aware that elevated BST does not always mean an MC disorder.

Keywords: tryptase, $\beta$-tryptase, hereditary $\alpha$-tryptasemia, mast cells, basal serum tryptase

\section{INTRODUCTION}

Mast cells (MCs) are tissue effector cells that participate in several physiologic and pathologic processes such as innate immunity, immunomodulation, allergy, autoimmunity, and neuroinflammation (1). Upon activation, MCs release preformed molecules stored in secretory granules, newly synthetized mediators, and several cytokines. On the stored proteases tryptase is a serine protease related to trypsin. Baseline serum tryptase (BST) levels correlate with MC burden and/or MC number in acute allergic reactions, thus providing a measure of MC activation (2). 
Mast cell disorders (MCD) can be associated to an increased number of mast cells, activation of MCs, or both. A recent consensus (3) has classified MC activation (MCA) disorders in primary mast cell activation syndrome (MCAS) - when clonality is present-secondary MCAS, and idiopathic MCAS. The criteria indicative of systemic MCA are: (a) typical clinical signs and symptoms, (b) substantial and transient increase in an MCderived mediator in biological fluids (being BST during or shortly after the acute event) compared to a baseline recorded either before the acute event or at least $24 \mathrm{~h}$ after all clinical signs and symptoms of the event have completely resolved, and (c) an objective major response of clinical symptoms to agents that attenuate the production or activity of MC-derived mediators (3). Recently, hereditary $\alpha$-tryptasemia $(\mathrm{H} \alpha \mathrm{T})$, which is associated with increased copy numbers of the TPSAB1 gene encoding $\alpha$-tryptase, has been included in the last consensus report of MCD (4).

The tryptase comprises different proteases, so far $\alpha, \beta, \gamma$, and $\delta$, which show minor differences in terms of their enzymatic properties (5). To date, the best characterized tryptase is the $\beta$-tryptase. Three $\beta$-tryptase subtypes have been described ( $\beta I$, $\beta$ II, and $\beta$ III). $\beta$-tryptase is stored in its active form, though it is maintained with little or no activity within the secretory granules due to the low $\mathrm{pH}$ value and stabilization mediated by other proteins. In the absence of the factors needed for stabilization, the structure dissociates into monomers that were initially considered to be inactive, though several studies have demonstrated the existence of active $\beta$-tryptase monomers (6). Compared to $\beta$-tryptase, $\alpha$-tryptase is in low levels in the circulation, without degranulation. Both enzymes have a 93$96 \%$ similarity in their amino acid sequences. In addition, other tryptases have been described: $\boldsymbol{\gamma}$-tryptase, which is less related to other tryptases and $\delta$-tryptase, which is similar to $\alpha$-tryptase in its amino acid sequence and is also constitutively secreted.

A region containing the human tryptase locus has been described in chromosome 16p13.3, containing at least four genes (7). The TPSG1 gene, encoding for $\gamma$-tryptase, is followed by the TPSB2 gene, which encodes for tryptases $\beta I I / \beta I I I$, and by the TPSAB1 gene, which encodes for $\alpha$-tryptase and $\beta$-tryptase. Lastly, the TPSD1 gene encodes for $\delta$-tryptase. Although the genes encoding for tryptases $\beta$ I and $\beta$ III have been previously localized within the aforementioned chromosome, there is some controversy regarding their precise position. $\mathrm{CpG}$ islands have been identified in this region, a fact that complicates the cloning and sequencing processes (7).

Familial occurrence of increased serum BST has been rarely described. Lyons et al. (8) reported that increases in the TPSAB1 gene, which codes for $\alpha$-tryptase, were associated with BST levels $>8 \mathrm{ng} / \mathrm{mL}$. This trait is inherited, and the condition is called hereditary $\alpha$-tryptasemia $(\mathrm{H} \alpha \mathrm{T})$. We had the opportunity to study four members of a family with elevated BST for 16 years (2003-2019) which correlated with a high expression of tryptase and gene dose.

Abbreviations: BST, basal serum tryptase; HAT or $\mathrm{H} \alpha \mathrm{T}$, hereditary $\alpha$-tryptasemia; $\mathrm{BM}$, bone marrow; MC, mast cell; MCD, mast cell disorder; MCAS, mast cell activation syndrome.

\section{PATIENTS AND METHODS}

\section{Ethics}

The study was approved by the local Ethics Committee of the University Hospital of Salamanca (PI120913) and an informed consent form was signed in all cases.

\section{Subjects and Clinical Assessments}

The index case was a patient in her fifties who in 3 years presented six events, without identifying known triggers, consisting of sudden episodes of shivering, abdominal pain, nausea, vomiting, and diarrhea, followed by muscular cramps; no cutaneous lesions, hypotension, or other symptoms appeared. The patient required hospitalization for these episodes, but symptoms resolved with supportive therapy. The index case had been studied by Internal Medicine where gastrointestinal, thyroid, suprarenal or celiac disease, carcinoid syndrome, neuroendocrine syndromes, autoimmunity, and porphyria were ruled out. The patient was then referred to the Department of Allergy. Physical exploration was unremarkable. Skin prick tests to aeroallergens and food extracts were negative. Total serum IgE was 21.6 $\mathrm{kU} / \mathrm{L}, \mathrm{C} 3, \mathrm{C} 4, \mathrm{CH} 100$, and C1-INH levels were normal, and parasite infections were ruled out. BST was $47.4 \mathrm{ng} / \mathrm{ml}$ (Thermo Scientific Phadia AB, Uppsala, Sweden). When repeated 2 months later, BST showed a value of $48.4 \mathrm{ng} / \mathrm{ml}$. A bone marrow (BM) study was later performed strictly following the proposed criteria (9): BM MCs morphology was analyzed in toluidine blue and May-Grünwald-Giemsa-stained smears (10) and disclosed no abnormalities. Immunophenotypical analysis of CD25 expression on BM MCs was performed by flow cytometry using a multiparameter 4-color immunofluorescence technique according to consensus procedures and criteria previously defined by the Spanish Network on mastocytosis (REMA) (11, 12). Flow cytometry showed $0.006 \%$ of MCs on BM and $<1 / 10^{5}$ cells on peripheral blood. Mast cells showed a normal phenotype (CD117++, CD45+, CD25-, CD2-, CD69 $9^{\text {low }}$, and $\operatorname{IgE}+$ ). Study of somatic activating codon Asp816-Val KIT mutation or other KIT mutations was performed in genomic DNA from fluorescence-activated cell-sorting purified populations of BM mast cells, neutrophils, eosinophils, monocytes, lymphocytes, $\mathrm{CD}_{3}{ }^{+}$hematopoietic progenitor and precursor cells, and nucleated red cells, as described elsewhere (13). No mutations were detected. Meanwhile, antihistamines were prescribed on a daily basis, but six new episodes appeared. During one of these episodes, acute serum tryptase could be determined, showing no significant increase $(35.9 \mathrm{ng} / \mathrm{ml})$, even when considering the rule of an increase in BST exceeding $20 \%$ of baseline value plus absolute $2 \mathrm{ng} / \mathrm{ml}$. The patient could fulfill one of the diagnostic criteria of MCAS (3), although clinical symptoms were not typical. Nevertheless, she had permanently increased BST without variation during acute episodes-although the participation of other putative mediators cannot be excluded-and she did not respond to anti-mast cell mediator treatment and, thus, a MCAS diagnosis was discarded. After these initial episodes, the index case has been asymptomatic up to date. In January 2019, her tryptase levels were $38.8 \mathrm{ng} / \mathrm{ml}$. 


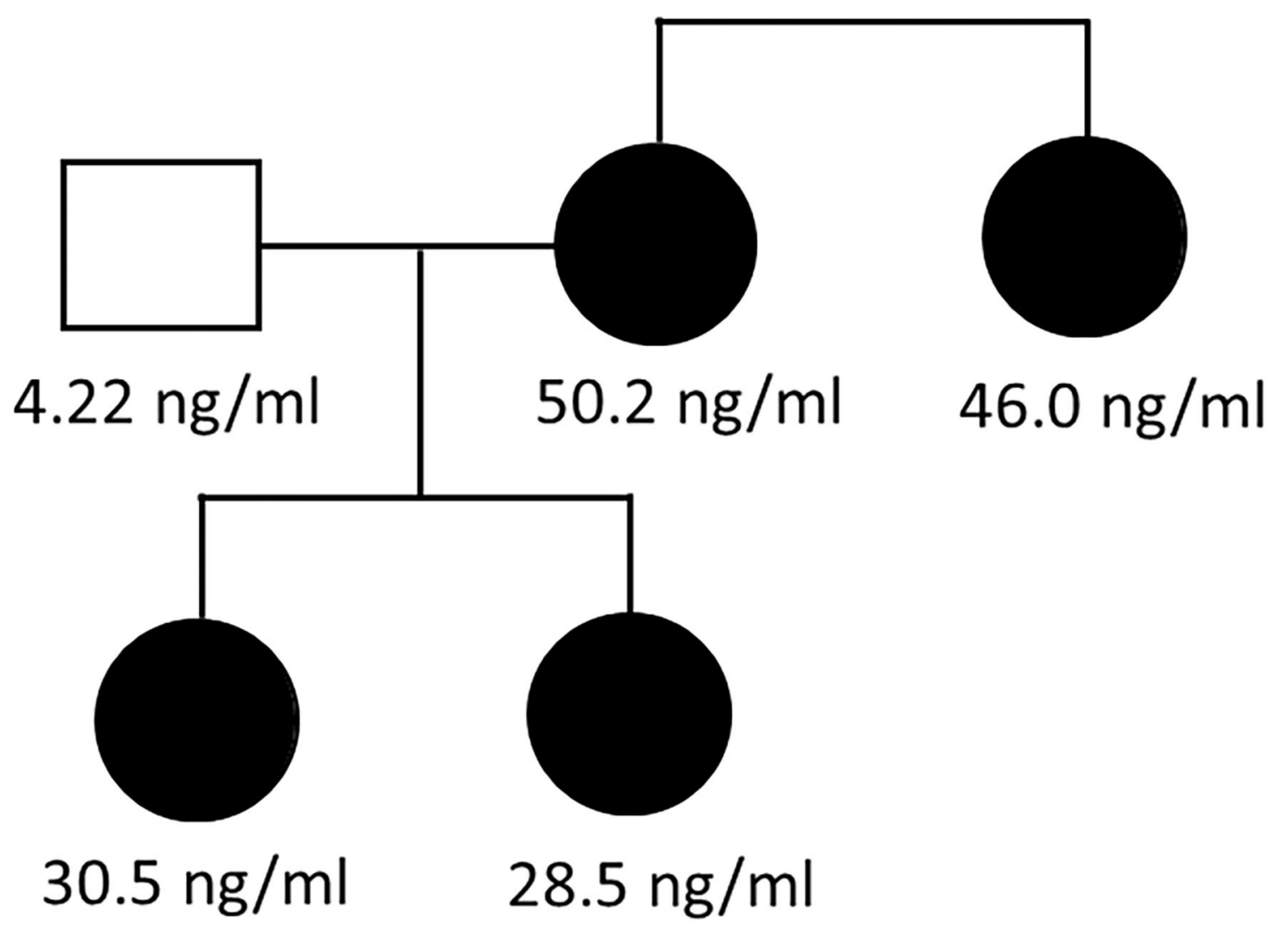

FIGURE 1 | Family pedigree. Family pedigree showing hereditary alpha-tryptasemia syndrome. Numbers indicate serum baseline tryptase concentration (in ng/ml) in the index case (I.2), her sister (I.3), and two daughters (II.1 and II.2); values were normal in her husband (I.1).

We carried out a determination of BST levels and genetic analysis to the index case, her sister, her two daughters, and her husband. All of them gave informed written consent to perform these procedures. Serum baseline tryptase levels were as follows: $50.2 \mathrm{ng} / \mathrm{ml}$ (index case, I.2); $30.5 \mathrm{ng} / \mathrm{ml}$ (daughter \#1, II.1); $28.5 \mathrm{ng} / \mathrm{ml}$ (daughter \#2, II.2), $46 \mathrm{ng} / \mathrm{ml}$ (sister, I.3), and $4.22 \mathrm{ng} / \mathrm{ml}$ (husband, I.1; Figure 1). The sister and the two daughters were completely asymptomatic, as well as the husband, so no BM biopsy was performed. Furthermore, the index case and his family has been followed for 14 years and they have all remained asymptomatic up to date. Two individuals were included as controls for the expression and gene dose analyses. The inclusion criteria were (i) no symptoms or history of allergy; (ii) no symptoms or history of asthma or other pulmonary diseases; (iii) negative skin prick tests to a battery of common aeroallergens; (iv) absence of first-degree relatives with a history of asthma or atopy; and (v) BST lower than $11.4 \mathrm{ng} / \mathrm{ml}$.

\section{Gene Expression Analysis}

RNA was obtained with the RiboPure ${ }^{\mathrm{TM}}$-Blood Kit (Ambion, Life Technologies, Paisley, UK) according to the manufacturer's instructions. cDNA samples were obtained with Superscript ${ }^{\mathrm{TM}}$ First-Strand Synthesis System for RT-PCR (Invitrogen, Life Technologies, Carlsbad, California, USA).
Quantitative expression experiments were performed in the control group and in family members following MIQE recommendations (14). The efficiency analysis of primers was previously performed for TPS (tryptase gene) forward 5'-GCGATGTGGACAATGATGAG-3' and reverse $5^{\prime}$-TTCCATTATGGGGACCTTCA-3' primers as well as for TBP (TATA box binding protein) forward $5^{\prime}$-ATAGGGATTCCGGGAGTCAT- $3^{\prime}$ and reverse $5^{\prime}$ GAACATCATGGATCAGAACAACA- $3^{\prime}$ primers (TBP was used as reference). Relative quantitative PCR (qPCR) was performed in a LightCycler 480 Instrument and using SYBR Green I Master (Roche, Indianapolis, IN, USA). The luminescence signal acquisition was obtained in the last cycle of amplification (unique acquisition) and in the melting curve (continuous acquisition). Two negative control samples were included and three replications per sample were performed.

Expression differences were calculated by the Livak method (15). The process was carried out in an accredited laboratory following ISO-15189.

\section{Gene-Dose Analysis}

A relative qPCR was carried out to determine the gene-dose of TPSAB1, TPSB2, and TPSD1 genes. The efficiency of TPSAB1 primers: forward 5'-CCAAAACACCACTGCTTCCT- $3^{\prime}$ and 
TABLE 1 | Family clinical features.

\begin{tabular}{|c|c|c|c|c|}
\hline & $\begin{array}{l}\text { BST } \\
(\mathrm{mcg} / \mathrm{ml})\end{array}$ & Symptoms & $\begin{array}{l}\text { Increased } \\
\text { BST during } \\
\text { crisis } \\
\text { (mcg/ml) }\end{array}$ & $\begin{array}{l}\text { Response of } \\
\text { clinical } \\
\text { symptoms to } \\
\text { HRB }\end{array}$ \\
\hline 1.2 & $\begin{array}{l}59.9 \text { (2003), } \\
62.2(2004), \\
46.4 \text { (2005), } \\
50.2(2008)\end{array}$ & $\begin{array}{l}\text { Episodes of } \\
\text { abdominalgia, } \\
\text { vomiting, } \\
\text { chills, } \\
\text { hypothermia, } \\
\text { syncope, } \\
\text { metabolic } \\
\text { acidosis, and } \\
\text { hypokalemia }\end{array}$ & No & No \\
\hline II.1 & 30.5 & Asymptomatic & - & \\
\hline 11.2 & 28.5 & Asymptomatic & - & \\
\hline 1.3 & 46.0 & Asymptomatic & - & \\
\hline 1.1 & 4.22 & Asymptomatic & - & \\
\hline
\end{tabular}

BST, Basal serum tryptase levels.

reverse 5'-AGGATAGGGAAGGGTCCTCA-3'; TPSB2 primers: forward 5'-CAGCGAGTGGGCATCGTT-3', and reverse $5^{\prime}$-TGCATCCAGTATCGGTCGC-3', and TPSD1 primers: forward $5^{\prime}$-GGGGTTTGGAGAGTCCCTTA- $3^{\prime}$ and reverse $5^{\prime}$-TCCACATAGCAAGTCCGTGA-3' was tested by generation of a standard curve with serial dilutions, using the slope of the regression line $[E=10$ (1-slope)]. Reactions were performed in triplicate in a final volume of $15 \mu \mathrm{l}$, including $50 \mathrm{ng}$ of genomic DNA, SYBR Green I Master (Roche Applied Science, IN, USA), and $0.4 \mu \mathrm{M}$ of each primer. Amplification was performed using the LightCycler 480 Instrument (Roche Applied Science, IN, USA). The qPCR protocol used an initial denaturation step $\left(95^{\circ} \mathrm{C}\right.$ for $\left.10 \mathrm{~s}\right)$ followed by amplification and quantification steps repeated for 45 cycles $\left(95^{\circ} \mathrm{C}\right.$ for $30 \mathrm{~s}, 60^{\circ} \mathrm{C}$ for $30 \mathrm{~s}$, and $72^{\circ} \mathrm{C}$ for $\left.30 \mathrm{~s}\right)$. GAPDH was considered as the reference gene and the copy number was estimated from the normalized ratio $2 \times 2-(\Delta \Delta \mathrm{Ct})$ using a DNA control obtained from a healthy subject. $\mathrm{qPCR}$ product quality was monitored using post-PCR melt curve analysis.

\section{Tryptase Gene Genotyping}

Genotyping of the TPSAB1 gene was performed by quantitative real-time digital PCR (qdPCR) using the Biomark ${ }^{\mathrm{TM}} \mathrm{HD}$ system (Fluidigm, South SanFrancisco, CA, USA). To detect copy number variation (CNV) in $\alpha$ and $\beta$ alleles, specific probes, as previously described in Lyons et al. (8), were used for qdPCR reaction according to the $37 \mathrm{~K}$ digital PCR protocol (Fluidigm). Data were analyzed using Digital PCR Analysis software (Fluidigm). Hereditary $\alpha$-tryptasemia $(\mathrm{H} \alpha \mathrm{T})$ was defined as three or more $\alpha$-tryptase copies or two $\alpha$-tryptase copies in the presence of three $\beta$-tryptase copies.

\section{Data Analysis}

The databases consulted to analyze the Tryptase genes were the Genome Browser of California University (http://genome.ucsc. edu/), Aceview (http://www.ncbi.nlm.nih.gov/IEB/Research/
TABLE 2 | TPSAB1 mRNA expression levels.

\begin{tabular}{lrr}
\hline Patient & $\boldsymbol{\Delta} \boldsymbol{\Delta} \mathbf{C t}$ & Fold \\
\hline I.2 & -5.09 & 33.99 \\
I.3 & -4.17 & 17.96 \\
I.1 & 1.76 & 0.29 \\
Control \#1 & -0.99 & 1.99 \\
Control \#2 & -0.44 & 1.35 \\
\hline
\end{tabular}

Acembly/), Genecards (http://www.genecards.or), and NCBI from the National Center for Biotechnology Information (http:// www.ncbi.nlm.nih.gov/projects/SNP/).

Statistical analysis was performed using SPSS 19.0 software (Chicago, Illinois, USA), the statistical power was analyzed with available software in http://www.dssresearch.conm/toolkit/ sscalc/size_a2.asp and http://statpages.org/proppowr.html.

\section{RESULTS}

We had the opportunity to study four members of a family with elevated BST for 16 years. The four members of the same family were the index case (I.2), her sister (I.3), and her two daughters (II.1 and II.2). BST values were normal in her husband (I.1) and controls (Figure 1 and Table 1). Additionally, KIT mutations were negative, and a clonal MCD was discarded after the performance of a BM biopsy. Furthermore, the patient has been followed for 14 years, and has been asymptomatic for the last 9 years (except for pruritus sine materia) despite the persistence of elevated BST (Table 1). The rest of the family has also been asymptomatic all this time. We consider that this family with elevated BST, in the absence of clinical symptoms, and without clonal MCs, has an asymptomatic $\mathrm{H} \alpha \mathrm{T}$.

We aimed to interrogate whether BST could correlate with mRNA expression and gene dose in this family. We detected an increase in the mRNA expression of tryptase genes in the family members compared to controls. Thus, patient I.2 showed a dramatic increment in fold change compared to control average (Table 2). Both patients I.2 and I.3 showed BST $>20 \mathrm{ng} / \mathrm{ml}$, which was higher (average $54.67 \mathrm{ng} / \mathrm{ml}$ ) for I.2 than for I.3 $(46 \mathrm{ng} / \mathrm{ml})$. The index case also presented the highest levels of tryptase gene expression. These levels correlated with a highly increased tryptase mRNA expression in those patients (Pearson $0.977, p=0.004$ ).

In addition, we detected an increase of the TPSAB1 gene dose in the family members, which correlated with BST levels (Pearson $0.868, p=0.011)$, whereas TPSB2 and TPSD1 showed a normal gene dose. The index case (I.2) and their relatives I.3, II.1, and II.2 had a higher copy number than the controls for TPSAB1. Considering two as the normal number of copies, we found: patient I. $2=4.13$; patient I. $3=4.47$; patient II. $1=4.57$; and patient II. $2=4.04$. These results of CNV were confirmed, with qdPCR revealing a hereditary copy number gain genotype $(3 \beta 2 \alpha)$ present in all family members studied (Table 3). 
TABLE 3 | Identified tryptase genotypes encoded at TPSAB1 and TPSB2.

\begin{tabular}{lll}
\hline Patient & Genotype & Phenotype \\
\hline I.2 & $3 \beta 2 \alpha$ & Hereditary $\alpha$-tryptasemia \\
I.3 & $3 \beta 2 \alpha$ & Hereditary $\alpha$-tryptasemia \\
II.1 & $3 \beta 2 \alpha$ & Hereditary $\alpha$-tryptasemia \\
I.2 & $3 \beta 2 \alpha$ & Hereditary $\alpha$-tryptasemia \\
I.1 & $3 \beta 1 \alpha$ & Conserved TPSAB1 copy number \\
Control & $3 \beta 1 \alpha$ & Conserved TPSAB1 copy number \\
\hline
\end{tabular}

\section{DISCUSSION}

We found four members of the same family with elevated BST that were followed-up for 16 years. The index case presented the highest BST and some symptoms that could be compatible with atypical symptoms of the release of MC mediators, but the patient did not fulfill all the diagnostic criteria of MCAS (3). Additionally, a clonal mast cell disorder was discarded in the index case by performing a BM biopsy, and KIT mutations studied were negative. Some cases of familial mastocytosis have been described (16-19). Molderings et al. (20) described a familial occurrence of systemic MC activation disease reporting that mutated disease-related operator and/or regulator genes could be responsible for the development of somatic mutations in KIT and other proteins involved in the regulation of mast cell activity. Recently, the entity known as hereditary alphahypertryptasemia has emerged. Lyons et al. (21) identified nine atopic subjects with persistent increases in BST in the absence of evidence for a clonal MCD. They found an autosomal dominant inheritance pattern of increased BST, which is in agreement with our family. Although they observed an increase in MC numbers on BM, none of the five index patients that underwent BM biopsy met the World Health Organization established criteria for the diagnosis of systemic mastocytosis (22) or the ones proposed for monoclonal MCA (3). Nevertheless, all of the patients were symptomatic. In addition, these authors also found that elevated BST identified a multisystem disorder associated with increased TPSAB1 copy number (8). Finally, Sabato et al. (23) reported a family with elevated BST and MCAS. They found elevated BST in seven relatives of three consecutive generations, suggesting a monogenic form of hypertryptasemia with autosomal dominant inheritance. Two patients were completely asymptomatic and a third one only had apathy and migraine with a normal BM biopsy. These three patients are similar to the two daughters (II.1, II.2) and the sister (I.3) of our index case.

We consider that this family with high BST in the absence of clinical symptoms and without clonal MCs has an asymptomatic familial hypertryptasemia or $\mathrm{H} \alpha \mathrm{T}$. We detected an increase in the mRNA expression of tryptase genes in the family members compared to controls. The index case also presented the highest BST levels which correlated with a highly increased tryptase mRNA expression. In addition, we detected an increase of TPSAB1 gene dose in patients which correlated with high BST levels in those patients. This agrees with Sabato et al. (24) that recently reported a TPSAB1 quintuplication in a highly symptomatic patient with clonal MC disease, remarking that individuals carrying three or more copies of $\alpha$-tryptase had higher BST and more symptoms than those carrying two copies.

We performed $\mathrm{CNV}$ analysis revealing a hereditary copy number gain phenotype $(3 \beta 2 \alpha)$ present in the index case (I.2), her sister (I.3), and her daughters (II.1 and II.2). Although the mRNA of patients II.1 and II.2 was not available, a good correlation between gene expression and BST levels was shown in the rest of the samples. Finally, other factors capable of modulating gene expression can be involved, such as epigenetic factors (25).

In conclusion, we present a family with $\mathrm{H} \alpha \mathrm{T}$, elevated BST, and mRNA gene expression in the absence of MC clonality. Unlike what has been reported to date, nearly all of them have remained asymptomatic during a long follow-up period. Typically, BSTs have been associated with having an MCD. However, $\mathrm{H} \alpha \mathrm{T}$ associates with increased copy numbers of the TPSAB1 gene, which leads to high BSTs (4) and may not be associated with the presence of usual MC-mediator release symptoms or may even be asymptomatic. Since an estimated 4$6 \%$ of the population has high levels of BST $(26,27), \mathrm{H} \alpha \mathrm{T}$ should be taken into account in the differential diagnosis of patients with symptoms of mastocyte activation and increased BST levels, not only to achieve a correct diagnosis and treatment but also to advise on prognosis and recommendations.

\section{DATA AVAILABILITY STATEMENT}

The raw data supporting the conclusions of this article will be made available by the authors, without undue reservation.

\section{ETHICS STATEMENT}

The studies involving human participants were reviewed and approved by the local Ethics Committee of the University Hospital of Salamanca (PI120913) and an informed consent was signed in all cases. The patients/participants provided their written informed consent to participate in this study.

\section{AUTHOR CONTRIBUTIONS}

LH-H, CS, ID, and MI-G conceived and planned the experiments. LH-H, EM-V, and AG-S carried out the experiments. EM, FL, and ID collect the samples. LH-H, CS, EM-V, AG-S, DG-O, ID, and MI-G contributed to the interpretation of the results. All authors provided critical feedback and helped shape the research, analysis, and manuscript. All authors agree to be accountable for the content of the work.

\section{FUNDING}

This research received funding from the Spanish Foundation of the Spanish Association of Allergy and Clinical Immunology (Sociedad Española de Alergologia e Inmunologia Clínica), the Council of Castilla y León, Education Counseling 
in the context of Regional Strategy of Scientist Research, Technological Development and Innovation 2007-2013, cofinancing from the European Social Fund, the Immunoallergic Association of Salamanca, and the Asthma, Allergic, and

\section{REFERENCES}

1. Theoharides TC, Valent P, Akin C. Mast cells, mastocytosis, and related disorders. N Engl J Med. (2015) 373:163-72. doi: 10.1056/NEJMra1409760

2. Vega-Castro A, Alonso-Llamazares A, Cárdenas R, Beitia JM, Mateo B, Alvarez-Twose I, et al. An increase in tryptase on the first day of hymenoptera venom immunotherapy might be a predictor of future systemic reactions during treatment. J Investig Allergol Clin Immunol. (2018) 28:305-11. doi: 10.18176/jiaci.0258

3. Valent P, Akin C, Bonadonna P, Hartmann K, Brockow K, Niedoszytko $\mathrm{M}$, et al. Proposed diagnostic algorithm for patients with suspected mast cell activation syndrome. J Allergy Clin Immunol Pract. (2019) 7:1125-33.e1. doi: 10.1016/j.jaip.2019.01.006

4. Weiler CR, Austen KF, Akin C, Barkoff MS, Bernstein JA, Bonadonna P, et al. AAAAI Mast Cell Disorders Committee Work Group Report: Mast cell activation syndrome (MCAS) diagnosis and management. J Allergy Clin Immunol. (2019) 144:883-96. doi: 10.1016/j.jaci.2019.08.023

5. Sommerhoff $\mathrm{CP}$, Schaschke N. Mast cell tryptase beta as a target in allergic inflammation: an evolving story. Curr Pharm Des. (2007) 13:313-32. doi: $10.2174 / 138161207779313579$

6. Fukuoka Y, Schwartz LB. Active monomers of human beta-tryptase have expanded substrate specificities. Int Immunopharmacol. (2007) 7:1900-8. doi: 10.1016/j.intimp.2007.07.007

7. Caughey GH. New developments in the genetics and activation of mast cell proteases. Mol Immunol. (2002) 38:1353-7. doi: 10.1016/S0161-5890(02)00087-1

8. Lyons JJ, Yu X, Hughes JD, Le QT, Jamil A, Bai Y, et al. Elevated basal serum tryptase identifies a multisystem disorder associated with increased TPSAB1 copy number. Nat Genet. (2016) 48:1564-9. doi: 10.1038/ng.3696

9. Valent $\mathrm{P}$, Akin C, Escribano L, Födinger M, Hartmann K, Brockow K, et al. Standards and standardization in mastocytosis: consensus statements on diagnostics, treatment recommendations and response criteria. Eur J Clin Invest. (2007) 37:435-53. doi: 10.1111/j.1365-2362.2007.01807.x

10. Sperr WR, Escribano L, Jordan JH, Schernthaner GH, Kundi M, Horny HP, et al. Morphologic properties of neoplastic mast cells: delineation of stages of maturation and implication for cytological grading of mastocytosis. Leuk Res. (2001) 25:529-36. doi: 10.1016/S0145-2126(01)00041-8

11. Escribano L, Diaz-Agustin B, López A, Núñez López R, García-Montero A, Almeida J, et al. Immunophenotypic analysis of mast cells in mastocytosis: when and how to do it. Proposals of the Spanish Network on Mastocytosis (REMA). Cytometry B Clin Cytom. (2004) 58:1-8. doi: 10.1002/cyto.b.10072

12. Escribano L, Orfao A, Díaz-Agustin B, Villarrubia J, Cerveró C, López $\mathrm{A}$, et al. Indolent systemic mast cell disease in adults: immunophenotypic characterization of bone marrow mast cells and its diagnostic implications. Blood. (1998) 91:2731-6. doi: 10.1182/blood.V91.8.2731.2731_2731_2736

13. Garcia-Montero AC, Jara-Acevedo M, Teodosio C, Sanchez ML, Nunez $\mathrm{R}$, Prados A, et al. KIT mutation in mast cells and other bone marrow hematopoietic cell lineages in systemic mast cell disorders: a prospective study of the Spanish Network on Mastocytosis (REMA) in a series of 113 patients. Blood. (2006) 108:2366-72. doi: 10.1182/blood-2006-04-0 15545

14. Taylor S, Wakem M, Dijkman G, Alsarraj M, Nguyen M. A practical approach to RT-qPCR-Publishing data that conform to the MIQE guidelines. Methods. (2010) 50:S1-S5. doi: 10.1016/j.ymeth.2010.01.005

15. Livak KJ, Schmittgen TD. Analysis of relative gene expression data using realtime quantitative PCR and the 2(-Delta Delta C(T)) Method. Methods. (2001) 25:402-8. doi: 10.1006/meth.2001.1262
Adverse Reactions networks for Cooperative Research in Health (ARADyAL) in association with the Instituto de Salud Carlos III (RD16/0006/0019), co-funding from the European Regional Development Fund (ERDF).
16. Broesby-Olsen S, Kristensen TK, Møller MB, Bindslev-Jensen C, Vestergaard $\mathrm{H}$; Mastocytosis Centre, Odense University Hospital (MastOUH). Adult-onset systemic mastocytosis in monozygotic twins with KIT D816V and JAK2 V617F mutations. J Allergy Clin Immunol. (2012) 130:806-8. doi: 10.1016/j.jaci.2012.04.013

17. Wöhrl S, Moritz KB, Bracher A, Fischer G, Stingl G, Loewe R. A c-kit mutation in exon 18 in familial mastocytosis. J Invest Dermatol. (2013) 133:839-41. doi: 10.1038/jid.2012.394

18. Zanotti R, Simioni L, Garcia-Montero AC, Perbellini O, Bonadonna P, Caruso B, et al. Somatic D816V KIT mutation in a case of adult-onset familial mastocytosis. J Allergy Clin Immunol. (2013) 131:605-7. doi: 10.1016/j.jaci.2012.11.040

19. Zhang LY, Smith ML, Schultheis B, Fitzgibbon J, Lister TA, Melo JV, et al. A novel K509I mutation of KIT identified in familial mastocytosis-in vitro and in vivo responsiveness to imatinib therapy. Leuk Res. (2006) 30:3738. doi: 10.1016/j.leukres.2005.08.015

20. Molderings GJ, Haenisch B, Bogdanow M, Fimmers R, Nöthen MM. Familial occurrence of systemic mast cell activation disease. PLoS One. (2013) 8:e76241. doi: 10.1371/journal.pone.0076241

21. Lyons JJ, Sun G, Stone KD, Nelson C, Wisch L, O'Brien M, et al. Mendelian inheritance of elevated serum tryptase associated with atopy and connective tissue abnormalities. J Allergy Clin Immunol. (2014) 133:1471-4. doi: 10.1016/j.jaci.2013.11.039

22. Valent P, Akin C, Hartmann K, Nilsson G, Reiter A, Hermine O, et al. Advances in the classification and treatment of mastocytosis: current status and outlook toward the future. Cancer Res. (2017) 77:1261-70. doi: 10.1158/0008-5472.CAN-16-2234

23. Sabato V, Van De Vijver E, Hagendorens M, Vrelust I, Reyniers E, Fransen E, et al. Familial hypertryptasemia with associated mast cell activation syndrome. J Allergy Clin Immunol. (2014) 134:1448-50.e3. doi: 10.1016/j.jaci.2014.06.007

24. Sabato V, Chovanec J, Faber M, Milner JD, Ebo D, Lyons JJ. First identification of an inherited TPSAB1 quintuplication in a patient with clonal mast cell disease. J Clin Immunol. (2018) 38:457-9. doi: 10.1007/s10875-018-0506-y

25. Molderings GJ. Transgenerational transmission of systemic mast cell activation disease-genetic and epigenetic features. Transl Res. (2016) 174:86-97. doi: 10.1016/j.trsl.2016.01.001

26. Fellinger C, Hemmer W, Wöhrl S, Sesztak-Greinecker G, Jarisch R, Wantke F. Clinical characteristics and risk profile of patients with elevated baseline serum tryptase. Allergol Immunopathol (Madr). (2014) 42:54452. doi: 10.1016/j.aller.2014.05.002

27. Gonzalez-Quintela A, Vizcaino L, Gude F, Rey J, Meijide L, Fernandez-Merino C, et al. Factors influencing serum total tryptase concentrations in a general adult population. Clin Chem Lab Med. (2010) 48:701-6. doi: 10.1515/CCLM.2010.124

Conflict of Interest: The authors declare that the research was conducted in the absence of any commercial or financial relationships that could be construed as a potential conflict of interest.

Copyright (๑) 2021 Hernández-Hernández, Sanz, Marcos-Vadillo, García-Sánchez, Moreno, Lorente, González-de-Olano, Dávila and Isidoro-García. This is an openaccess article distributed under the terms of the Creative Commons Attribution License (CC BY). The use, distribution or reproduction in other forums is permitted, provided the original author(s) and the copyright owner(s) are credited and that the original publication in this journal is cited, in accordance with accepted academic practice. No use, distribution or reproduction is permitted which does not comply with these terms. 